\title{
Bioflavonoids as potential target inhibitors in COVID-19: An in silico analysis
}

\author{
Uma Sankar GORLA 1 * (D), Koteswara Rao GSN 1 (D), Umasankar KULANDAIVELU 1 (D), \\ Rajasekhar Reddy ALAVALA 1 (D), Subham DAS 2 (D), Alex JOSEPH 2 (1) \\ 1 College of Pharmacy, Koneru Lakshmaiah Education Foundation, Vaddeswaram, Andhra Pradesh, India. \\ 2 Department of Pharmaceutical Chemistry, Manipal College of Pharmaceutical Sciences, Manipal Academy of Higher \\ Education, Manipal, Karnataka, India. \\ * Corresponding Author. E-mail: umasankargorla@gmail.com (U.S.G.); Tel. +91-850-044 4400.
}

Received: 20 January 2021 / Revised: 08 July 2021/ Accepted: 17 July 2021

\begin{abstract}
COVID-19, a respiratory pandemic associated with morbidity and mortality due to the lack of FDA approved drugs for the appropriate preventive or treatment strategies. Repurposed drugs such as antiviral and antimalarials are in clinical trials for the development of novel therapeutic agents for the treatment of SARS-CoV-2 infection. The main protease (Mpro) digests replicase polyprotein to generate non-structural proteins and an endoribonuclease (NendoU), a non-structural protein acts as possible targets because of their prominent role in the replication of SARS-CoV-2. In the current study, the bioflavonoids that passed the Lipinski rule were subjected to in silico molecular docking on SARS-CoV-2 main protease and endoribonuclease using Molegro Virtual Docker v6.0. Molecular dynamic simulation studies $(20 \mathrm{~ns})$ were carried out to study protein-ligand complex stability by using Schrodinger, LLC's Maestro Molecular Platform (version 11.8). ADMET properties, target and antiviral potentials were predicted for the top interacting bioflavonoids and significant data were reported. The parameters such as MolDock scores, ReRank scores and interaction poses were predicted for the top interacting phytocompound. In silico analysis showed that hesperetin and malvidin bind effectively at the active site of Mpro and NendoU with a MolDock score of 100.78 and -86.51 respectively. Molecular dynamic simulations have shown that the protein-ligand complex was stable and exhibits good binding interactions with various amino acids. MM-GBSA studies showed $-52.51 \pm 5.01$ and 22.80 \pm 3.04 free binding energies for hesperetin and malvidin respectively. The current research created a new perspective in understanding hesperetin and malvidin as potent Mpro and NendoU inhibitors, and further research may confirm their therapeutic potentials in COVID-19.
\end{abstract}

KEYWORDS: Dynamic simulation studies; SARS-CoV-2; flavonoids; in silico molecular docking; main protease.

\section{INTRODUCTION}

COVID-19, a pandemic respiratory disease triggered by a novel single-stranded RNA virus named as "SARS-CoV-2" [1]. As of 19 January 2021, WHO reported 9,41,24,612 cases globally in 223 countries including 20,34,527 deaths for the 2019 China Corona outbreak and it was declared as a global health emergency (https://www.who.int/emergencies/diseases/novel-coronavirus-2019). COVID-19 is a highly contagious disease associated with morbidity and mortality. Millions are quarantined, and pandemic has driven the world economy into recession [2]. Severe acute respiratory syndrome coronavirus 2 (SARS-CoV-2) are positive-sense, betacoronavirus $(\beta \mathrm{CoV})$ spreading across the globe exponentially due to rapid human-tohuman transmission [3]. CoV comprises four structural proteins: Spike protein (S), envelop protein (E), and membrane protein $(\mathrm{M})$ that are responsible for viral coat formation, while nucleocapsid phosphoprotein $(\mathrm{N})$ is involved in viral genomic RNA packing. SARS-CoV-2 spike protein binds with angiotensin-converting enzyme 2 (carboxypeptidase) receptor and invades host cell for replication [4]. The viral replicase genome encodes two open reading frame genes (ORF1a and ORF1b), that are translated into two polyproteins, pp1a and $\mathrm{pp} 1 \mathrm{~b}$. These polyproteins were pre-processed and fragmented by viral proteases into 16 non-structural proteins (NSPs), which are assembled into replication transcription complex and exhibit multiple enzymatic activity [5].

The comprehensive proteolytic cleavage of polyproteins was primarily performed by main protease (Mpro), also known as 3C-like protease (3CLpro) [6]. The Mpro exists in homodimer and has Cys-His dyad on

How to cite this article: Gorla US, GSN KR, Kulandaivelu U, Alavala RR, Das S, Joseph A. Bioflavonoids as potential target inhibitors in COVID-19: An in silico analysis. J Res Pharm. 2021; 25(6): 982-997. 
active site which shows protease activity. Mpro acts as a key enzyme in the digestion of replicase polyprotein (C-terminus) at 11 conserved sites to generate non-structural proteins, which plays a vital role in mediating viral replication and transcription and serves as an attractive target for discovery and development of antivirals [7]. One of those non-structural proteins, endoribonuclease (NendoU) is a $\mathrm{Mn}^{2+}$-dependent nidoviral uridylate-specific endoribonuclease that performs various vital functions associated with RNA processing [8]. Nsp15 also acts as interferon (IFN) antagonist and inhibits interferon- $\beta$ production through an endonuclease activity-independent mechanism. Due to its endoribonuclease activity in the replication of SARS-CoV-2, NendoU acts as a potent target for inhibiting COVID-19 virulence.

Currently, SARS-CoV-2 intermediate host remains unknown, and due to the lack of FDA approved drugs for the treatment of human coronavirus infection and vaccines to prevent COVID-19, research against SARS-CoV-2 is ongoing globally [9]. Furthermore, there are many SARS-CoV-2 proteins that have been reported as possible targets for drugs [10]. Antivirals such as Lopinavir/Ritonavir (Kaletra ${ }^{\circledR}$ ) along with arbidol and Shufeng Jiedu Capsule, Chinese traditional herbal medicines were used in preliminary clinical trials for the development of novel therapeutic agents. Hydroxychloroquine and azithromycin, an antimalarial-macrolide combinational therapy results an open-label non-randomized clinical trial [11]. Natural phytocompounds serve as an excellent source to discover novel antivirals, to uncover structureactivity relationships and to establish successful therapeutic strategies against coronavirus infections [12]. There is an urgent need for the immediate development of phytocompounds for effective prevention and treatment approach for COVID-19 outbreak. Flavonoids, natural polyphenolic phytocompounds present in grains, cereals, vegetables, tea, flowers, fruits, red wine, etc and so forth have beneficial effects on health and exhibit anti-oxidative [13], anti-inflammatory [14], anti-bacterial [15], anti-carcinogenic [16], anti-proliferative [17], antiviral [18] and anti-estrogenic [19] properties. In fact, certain flavonoids have found to minimize the replication of viral genomic RNA and inhibits protein synthesis [20]. In the current findings, molecular docking and bioinformatics have been used to predict potential antiviral activity of flavonoids against SARS$\mathrm{CoV}-2$. In the current research, we have predicted ADMET properties and antiviral potentials using PreADMET and PASS online tools and screened certain flavonoids against possible protein targets of SARS$\mathrm{CoV}-2$ such as viral main protease (Mpro) and endoribonuclease (NSP15/NendoU) through in silico molecular docking using Molegro Virtual Docker v6.0 and molecular dynamic simulation studies using Schrodinger, LLC's Maestro Molecular Platform v11.8.

\section{RESULTS}

\subsection{Molecular descriptor analysis}

The physicochemical properties were predicted and the drug-likeness scores showed zero violations and found in accordance with Lipinski rule (Molecular weight $<500 \mathrm{Da}$; Consensus octanol-water partition coefficient < 5; number of H-bond acceptors < 10 and number of H-bond donors < 5) for all the selected phytocompounds. The molecular descriptor analysis indicated that the top interacting phytocompounds could have better solubility, absorption and permeation (Table 1).

Table 1. Drug-likeness descriptor values (Lipinski properties) of the top interacting ligands.

\begin{tabular}{ccccc}
\hline Name of the ligand & MW $(\mathbf{g} / \mathbf{m o l})$ & $\mathbf{C ~} \mathbf{L o g} \boldsymbol{P}_{\mathbf{o} / \mathbf{w}}$ & $\mathbf{n O N}$ & $\mathbf{n O H N H}$ \\
\hline Hesperetin & 302.28 & 1.91 & 6 & 3 \\
Malvidin & 331.30 & 0.86 & 7 & 4 \\
Peonidin & 301.27 & 0.83 & 6 & 4 \\
Silymarin & 482.44 & 1.51 & 10 & 5 \\
Quercetin & 302.24 & 1.23 & 7 & 5 \\
Morin & 302.24 & 1.20 & 7 & 5 \\
Diosmetin & 300.26 & 2.19 & 6 & 3 \\
Isorhamnetin & 316.26 & 1.65 & 7 & 4 \\
Luteolin & 286.24 & 1.73 & 6 & 4 \\
\hline
\end{tabular}

\subsection{ADMET analysis}

Early assessment of ADMET properties such as absorption, distribution, metabolism, excretion and toxicity are equally significant to demonstrate high biological activity of the phytocompound at the therapeutic target in the organism. In silico ADMET prediction relies on molecular structure of phytocompounds which reduces the cost and time of drug discovery and development [21]. The substantial properties of all the top 
three interacting phytocompounds were predicted by using PreADMET computational tool and represented in the Table 2.

\subsection{Validation analysis of the target protein}

The MolDock score of the co-crystalized (internal) ligand and extracted internal ligand of the docked target protein-ligand complex structures served as control docking models as represented in Table 3 . The docking outcomes showed that Molegro Virtual Docker v6.0 determined the optimal orientation of the cocrystalized ligands.

Table 2. Pharmacokinetic and toxicological predictions of the top interacting ligands.

\begin{tabular}{cccccc}
\hline Name of the ligand & Hesperetin & Malvidin & Peonidin & Silymarin & Quercetin \\
\hline Human intestinal absorption (\%) & 87.19 & 83.10 & 93.43 & 78.55 & 63.48 \\
Skin permeability (log Kp, cm/hr) & -4.18 & -4.20 & -4.10 & -4.23 & -4.43 \\
CaCo cell permeability (nm/sec) & 7.00 & 1.75 & 1.65 & 4.84 & 3.41 \\
BBB penetration (Cbrain/C blood) & 0.22 & 0.05 & 0.07 & 0.06 & 0.17 \\
Water solubility (mg/L) & 90.92 & 143.50 & 68.40 & 1.09 & 96.43 \\
Buffer solubility (mg/L) & 222.19 & 789.06 & 248.34 & 9.00 & 64.47 \\
CYP2C19 inhibition & Inhibitor & Inhibitor & Inhibitor & Inhibitor & Inhibitor \\
CYP2C9 inhibition & Inhibitor & Inhibitor & Inhibitor & Inhibitor & Inhibitor \\
CYP2D6 inhibition & Non & Non & Non & Non & Non \\
CYP3A4 inhibition & Inhibitor & Inhibitor & Inhibitor & Inhibitor & Inhibitor \\
P-glycoprotein inhibition & Non & Non & Non & Non & Non \\
Plasma protein binding $\%$ & 96.79 & 94.94 & 100 & 87.75 & 93.23 \\
Mutagenicity (Ames test) & Mutagen & Mutagen & Mutagen & Mutagen & Mutagen \\
Carcinogenicity (Mouse) & Negative & Negative & Negative & Negative & Negative \\
Carcinogenicity (Rats) & Positive & Positive & Positive & Negative & Positive \\
\hline
\end{tabular}

Table 3. MolDock score of the co-crystalized (internal) ligand and extracted internal ligand of the docked target protein-ligand complex structures.

\begin{tabular}{ccccc}
\hline PDB ID & $\begin{array}{c}\text { Co-crystalized } \\
\text { ligand (internal) }\end{array}$ & PDB Ligand ID & $\begin{array}{c}\text { Co-crystalized ligand } \\
\text { (internal) }\end{array}$ & $\begin{array}{c}\text { extracted internal } \\
\text { ligand }\end{array}$ \\
\hline 6LU7 & N3 & PRD_002214 & -208.09 & -208.09 \\
6W01 & Citric acid & CIT & -86.97 & -86.97 \\
\hline
\end{tabular}

\subsection{Molecular docking analysis}

Approximately 38 flavonoids were selected in accordance with the Lipinski rule, based on molecular descriptor properties. The potential biological activity of selected phytocompounds against SARS-CoV-2 target proteins was evaluated using molecular docking studies. The docking interactions of co-crystalized and selected ligands with viral main protease (Mpro) and endoribonuclease (NendoU) using Molegro Virtual Docker v6.0 were shown in Figure 2 and 3 respectively. The MolDock, ReRank and HBond scores of the top interacting phytocompounds were compared with the co-crystalized inhibitor (N3) of Mpro and with each other in case of NendoU enzyme due to absence of validated inhibitors for SARS-CoV-2 as shown in Table 4. The amino acid residues of the target proteins and the atoms of top interacting phytocompounds involved in hydrogen bonding and their bond lengths were summarized in Table 5 and 6. In silico analysis showed that hesperetin and malvidin bind effectively at the active sites of Mpro and NendoU with a MolDock score of 100.78 and -86.51 respectively.

\subsection{Target and antiviral prediction analysis}

In silico pharmacological target and activity prediction offers a focussed, efficient approach in the process of drug discovery and development [22]. The analysis predicted that hesperetin targets $20 \%$ of protease, $16 \%$ of lyase, $16 \%$ of enzymes, $8 \%$ of oxidoreductases, $8 \%$ of family A GPCR, $8 \%$ of cytochrome P450, $8 \%$ of nuclear receptor, $8 \%$ of primary active transporter, $4 \%$ of taste family GPCR and $4 \%$ of secreted protein with antiviral property against influenza, rhinovirus, herpes and hepatitis B while malvidin targets $26.7 \%$ of kinase, $20 \%$ of protease, $13.3 \%$ of nuclear receptor, $6.7 \%$ of enzyme, $6.7 \%$ of electrochemical transporter, $6.7 \%$ of lyase, $6.7 \%$ of membrane receptor, $6.7 \%$ of adhesion and $6.7 \%$ of cytosolic protein with antiviral property against influenza, influenza A, rhinovirus, herpes and hepatitis B (Figure 4). 

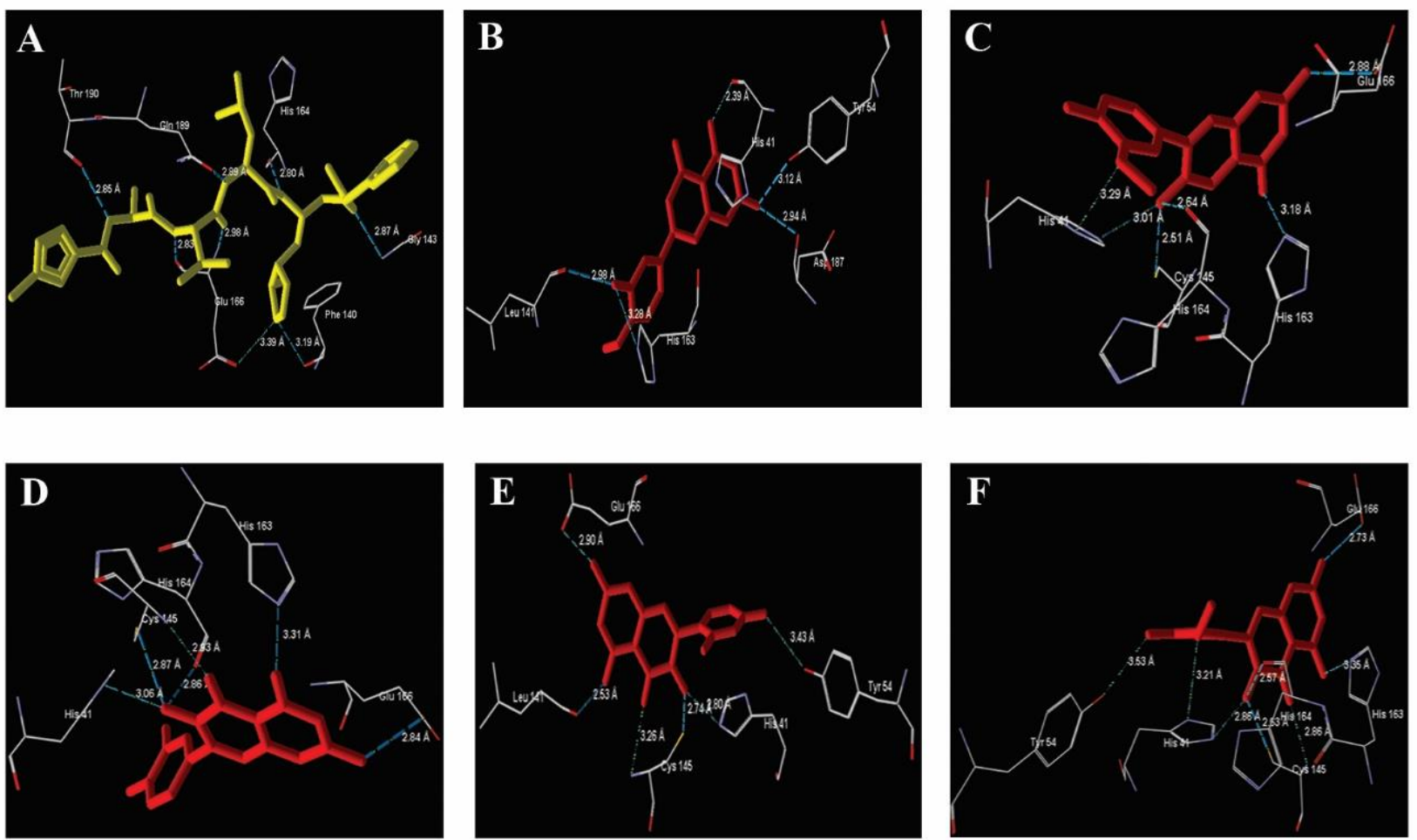

Figure 2. Molecular docking interactions of SARS-CoV-2 main protease Mpro and the atoms of the top 5 interacting ligands (A) Co-crystalized inhibitor N3, (B) Hesperetin, (C) Peonidin, (D) Quercetin, (E) Morin, (F) Isorhamnetin.
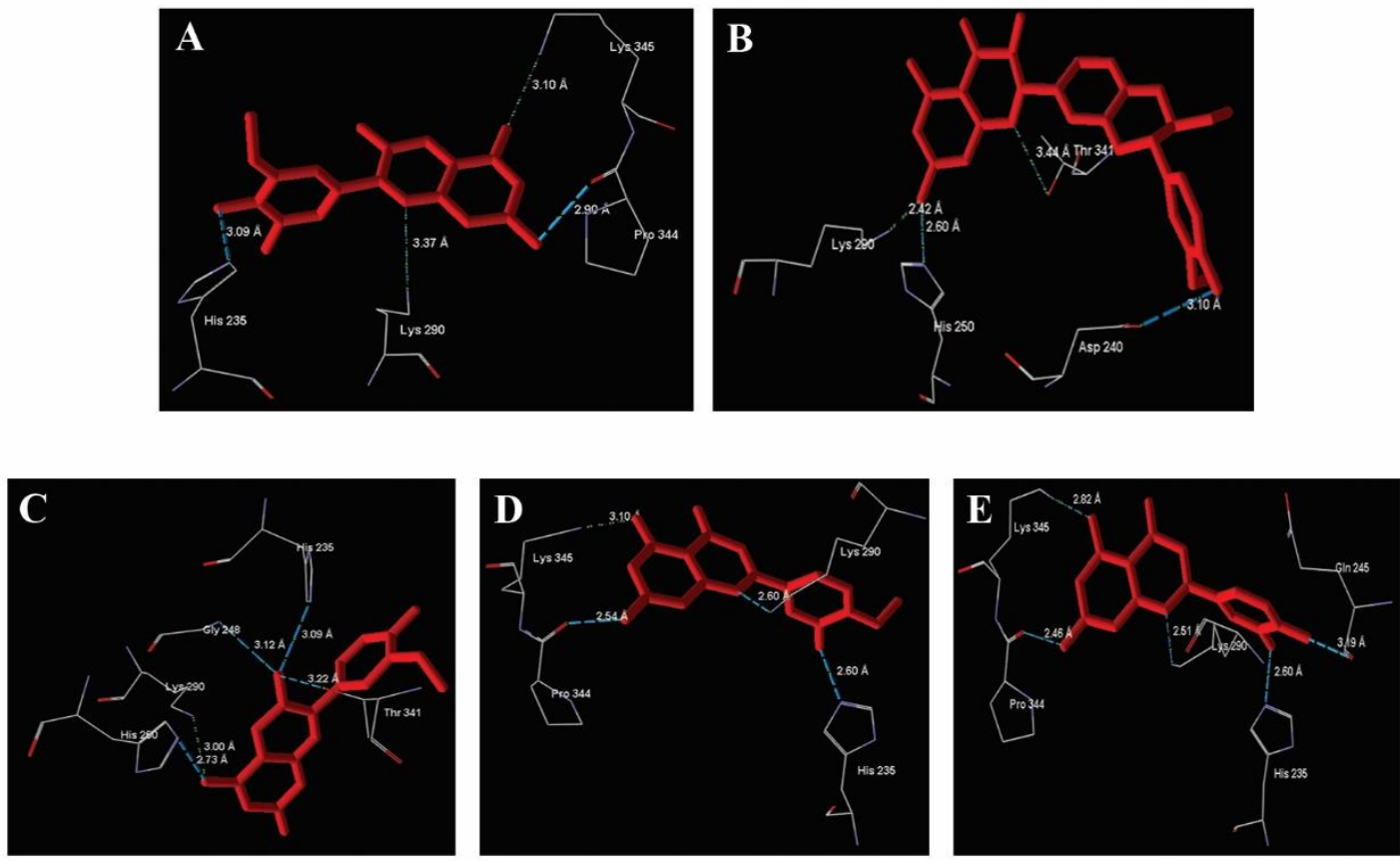

Figure 3. Molecular docking interactions of SARS-CoV-2 endoribonuclease (NendoU) and the atoms of the top 5 interacting ligands (A) Malvidin, (B) Silymarin, (C) Peonidin, (D) Diosmetin, (E) Luteolin.

\subsection{Binding free energy (MM-GBSA) studies}

To measure the binding energy of the top interacting ligands in each class with selected docked poses, the Prime MM-GBSA was employed. In the docked pose, all ligands demonstrated stability with $\Delta G$ binding energy $>-20 \mathrm{Kcal} / \mathrm{mol}$ (Table 7). 
Table 4. MolDock score and ReRank scores of the top interacting bioactive phytocompounds.

\begin{tabular}{ccccc}
\hline Target protein & ligand & MolDock score & ReRank score & HBond score \\
\hline Mpro (6LU7) & N3 (co-crystalized ligand) & -208.09 & -162.49 & -14.78 \\
& Hesperetin & -100.78 & -74.32 & -10.68 \\
& Peonidin & -99.77 & -50.55 & -10.75 \\
& Quercetin & -97.53 & -81.33 & -8.52 \\
& Morin & -96.63 & -42.61 & -13.42 \\
NendoU & Isorhamnetin & -95.93 & -42.37 & -12.70 \\
(6W01) & Malvidin & -86.51 & -54.63 & -9.99 \\
& Silymarin & -81.19 & -74.40 & -8.30 \\
& Peonidin & -80.56 & -63.24 & -11.05 \\
& Diosmetin & -80.18 & -47.52 & -9.46 \\
& Luteolin & -79.85 & -63.02 & -10.90 \\
\hline
\end{tabular}

Table 5. Amino acid residues of Mpro and the atoms of the top interacting ligands involved in hydrogen bonding and their bond lengths.

\begin{tabular}{|c|c|c|c|c|c|c|c|}
\hline \multicolumn{4}{|c|}{ Top interacting ligands } & \multicolumn{3}{|c|}{ Target Protein (Mpro) } & \multirow{2}{*}{$\begin{array}{c}\text { Bond } \\
\text { length } \\
\left(A^{\circ}\right) \\
\end{array}$} \\
\hline Name & $\begin{array}{c}\text { PubChem } \\
\text { ID }\end{array}$ & Structure & Ligand atom & AA Residues & PDB atom ID & $\begin{array}{c}\text { PDB atom } \\
\text { name }\end{array}$ & \\
\hline \multirow{8}{*}{$\begin{array}{l}\text { N3 (Co- } \\
\text { crystalized } \\
\text { ligand) }\end{array}$} & \multirow{8}{*}{7885280} & & $\mathrm{~N}$ (Donor) amide & His164 & 1266 & $\mathrm{O}$ (Acceptor) & 2.80 \\
\hline & & & $\mathrm{N}$ (Donor) amide & Glu166 & 1284 & $\mathrm{O}$ (Acceptor) & 2.83 \\
\hline & & & N (Donor) amide & Thr190 & 1469 & $\mathrm{O}$ (Acceptor) & 2.85 \\
\hline & & & O (Acceptor) carboxyl & Gly143 & 1105 & $\mathrm{~N}$ (Donor) & 2.87 \\
\hline & & & $\mathrm{N}$ (Donor) amide & Gln189 & 1464 & $\mathrm{O}$ (Acceptor) & 2.89 \\
\hline & & & O (Acceptor) carbonyl & Glu166 & 1281 & N (Donor) & 2.98 \\
\hline & & & $\mathrm{N}$ (Donor) amide & Phe140 & 1081 & O (Acceptor) & 3.19 \\
\hline & & & $\mathrm{N}$ (Donor) amide & Glu166 & 1288 & $\mathrm{O}$ (Acceptor) & 3.39 \\
\hline \multirow{5}{*}{ Hesperetin } & \multirow{5}{*}{72281} & & O (Donor) enol & His41 & 306 & O (Acceptor) & 2.39 \\
\hline & & & O (Donor) enol & Asp187 & 1441 & O (Acceptor) & 2.94 \\
\hline & & & O (Donor) enol & Leu141 & 1092 & O (Acceptor) & 2.98 \\
\hline & & & O (Both) enol & Tyr54 & 414 & O (Both) & 3.12 \\
\hline & & & $\mathrm{O}$ (Donor) enol & His163 & 1262 & $\mathrm{~N}$ (Acceptor) & 3.28 \\
\hline \multirow{6}{*}{ Peonidin } & \multirow{6}{*}{441773} & & O (Acceptor) enol & Cys145 & 1120 & S (Donor) & 2.51 \\
\hline & & & O (Donor) enol & His164 & 1265 & $\mathrm{O}$ (Acceptor) & 2.64 \\
\hline & & & O (Donor) enol & Glu166 & 1288 & O (Acceptor) & 2.88 \\
\hline & & & O (Donor) enol & His41 & 312 & $\mathrm{~N}$ (Acceptor) & 3.01 \\
\hline & & & $\mathrm{O}$ (Donor) enol & His163 & 1262 & $\mathrm{~N}$ (Acceptor) & 3.18 \\
\hline & & & $\mathrm{O}$ (Acceptor) enol & His41 & 309 & N (Donor) & 3.29 \\
\hline \multirow{6}{*}{ Quercetin } & \multirow{6}{*}{5280343} & & O (Donor) enol & Glu166 & 1288 & O (Acceptor) & 2.84 \\
\hline & & & O (Donor) enol & His164 & 1266 & O (Acceptor) & 2.86 \\
\hline & & & $\mathrm{O}$ (Acceptor) enol & Cys145 & 1120 & $\mathrm{~S}$ (Donor) & 2.87 \\
\hline & & & O (Acceptor) carbonyl & Cys145 & 1115 & N (Donor) & 2.93 \\
\hline & & & O (Donor) enol & His41 & 312 & N (Acceptor) & 3.06 \\
\hline & & & O (Donor) enol & His163 & 1262 & $\mathrm{~N}$ (Acceptor) & 3.31 \\
\hline \multirow{6}{*}{ Morin } & \multirow{6}{*}{5281670} & & O (Donor) enol & Leu141 & 1092 & O (Acceptor) & 2.53 \\
\hline & & & $\mathrm{O}$ (Acceptor) enol & Cys145 & 1120 & $\mathrm{~S}$ (Donor) & 2.74 \\
\hline & & & $\mathrm{O}$ (Donor) enol & His41 & 312 & $\mathrm{~N}$ (Acceptor) & 2.80 \\
\hline & & & O (Donor) enol & Glu166 & 1288 & O (Acceptor) & 2.90 \\
\hline & & & O (Acceptor) carbonyl & Cys145 & 1115 & N (Donor) & 3.26 \\
\hline & & & O (Both) enol & Tyr54 & 414 & O (Both) & 3.43 \\
\hline \multirow{8}{*}{ Isorhamnetin } & \multirow{8}{*}{5281654} & & O (Donor) enol & His164 & 1266 & $\mathrm{O}$ (Acceptor) & 2.57 \\
\hline & & & O (Acceptor) enol & Cys 145 & 1120 & $\mathrm{~S}$ (Donor) & 2.63 \\
\hline & & & $\mathrm{O}$ (Donor) enol & Glu166 & 1288 & $\mathrm{O}$ (Acceptor) & 2.73 \\
\hline & & & O (Donor) enol & His41 & 312 & $\mathrm{~N}$ (Acceptor) & 2.86 \\
\hline & & & O (Acceptor) carbonyl & Cys145 & 1115 & N (Donor) & 2.86 \\
\hline & & & $\mathrm{O}$ (Acceptor) enol & His41 & 309 & N (Donor) & 3.21 \\
\hline & & & $\mathrm{O}$ (Donor) enol & His163 & 1262 & $\mathrm{~N}$ (Acceptor) & 3.35 \\
\hline & & & O (Both) enol & Tyr54 & 414 & O (Both) & 3.53 \\
\hline
\end{tabular}


Table 6. Amino acid residues of NendoU and the atoms of the top interacting ligands involved in hydrogen bonding and their bond lengths.

\begin{tabular}{|c|c|c|c|c|c|c|c|}
\hline \multicolumn{4}{|c|}{ Top interacting ligands } & \multicolumn{3}{|c|}{ Target Protein (NendoU) } & \multirow{2}{*}{$\begin{array}{l}\text { Bond } \\
\text { length } \\
\left(\mathrm{A}^{\circ}\right)\end{array}$} \\
\hline Name & $\begin{array}{c}\text { PubChem } \\
\text { ID }\end{array}$ & \multirow[t]{5}{*}{ Structure } & Ligand atom & $\begin{array}{c}\text { AA } \\
\text { Residues }\end{array}$ & $\begin{array}{c}\text { PDB } \\
\text { atom } \\
\text { ID }\end{array}$ & $\begin{array}{l}\text { PDB atom } \\
\text { name }\end{array}$ & \\
\hline \multirow{4}{*}{ Malvidin } & \multirow{4}{*}{159287} & & $\mathrm{O}$ (Donor) enol & Pro344 & 5580 & $\mathrm{O}$ (Acceptor) & 2.90 \\
\hline & & & O (Donor) enol & His 235 & 4717 & $\mathrm{~N}$ (Acceptor) & 3.09 \\
\hline & & & O (Acceptor) enol & Lys345 & 5592 & N (Donor) & 3.10 \\
\hline & & & O (Acceptor) oxenium & Lys290 & 5151 & $\mathrm{~N}$ (Donor) & 3.37 \\
\hline \multirow{4}{*}{ Silymarin } & \multirow{4}{*}{31553} & & O (Acceptor) enol & Lys290 & 5151 & N (Donor) & 2.42 \\
\hline & & & O (Donor) enol & His 250 & 4832 & N (Acceptor) & 2.60 \\
\hline & & & O (Donor) enol & Asp240 & 4756 & O (Acceptor) & 3.10 \\
\hline & & & O (Acceptor) enol & Thr341 & 5552 & $\mathrm{O}$ (Donor) & 3.44 \\
\hline \multirow{5}{*}{ Peonidin } & \multirow{5}{*}{441773} & & O (Donor) enol & His250 & 4832 & N (Acceptor) & 2.73 \\
\hline & & & O (Acceptor) enol & Lys290 & 5151 & N (Donor) & 3.00 \\
\hline & & & O (Donor) enol & His235 & 4717 & N (Acceptor) & 3.09 \\
\hline & & & O (Acceptor) enol & Gly248 & 4811 & N (Donor) & 3.12 \\
\hline & & & O (Both) enol & Thr341 & 5552 & O (Both) & 3.22 \\
\hline \multirow{4}{*}{ Diosmetin } & \multirow{4}{*}{5281612} & & O (Donor) enol & Pro344 & 5580 & O (Acceptor) & 2.54 \\
\hline & & & $\mathrm{O}$ (Donor) enol & His235 & 4717 & $\mathrm{~N}$ (Acceptor) & 2.60 \\
\hline & & & $\mathrm{O}$ (Acceptor) enol & Lys290 & 5151 & N (Donor) & 2.60 \\
\hline & & & O (Acceptor) enol & Lys345 & 5592 & N (Donor) & 3.10 \\
\hline \multirow{5}{*}{ Luteolin } & \multirow{5}{*}{5280445} & & O (Donor) enol & Pro344 & 5580 & O (Acceptor) & 2.46 \\
\hline & & & O (Acceptor) enol & Lys290 & 5151 & N (Donor) & 2.51 \\
\hline & & & O (Donor) enol & His235 & 4717 & N (Acceptor) & 2.60 \\
\hline & & & O (Acceptor) enol & Lys345 & 5592 & N (Donor) & 2.82 \\
\hline & & & O (Donor) enol & Gln245 & 4793 & O (Acceptor) & 3.19 \\
\hline
\end{tabular}

Table 7. MM-GBSA binding free energy calculation results of the top interacting bioactive phytocompounds.

\begin{tabular}{ccc}
\hline Target protein & ligand & MM-GBSA $\Delta$ G binding score (Kcal/mol) \\
\hline Mpro (6LU7) & Hesperetin & $-52.51 \pm 5.01$ \\
& Peonidin & $-48.43 \pm 4.82$ \\
& Quercetin & $-37.98 \pm 3.67$ \\
& Morin & $-23.93 \pm 3.08$ \\
& Isorhamnetin & $-40.54 \pm 4.06$ \\
NendoU (6W01) & Malvidin & $-22.80 \pm 3.04$ \\
& Silymarin & $-21.82 \pm 3.21$ \\
& Peonidin & $-22.35 \pm 3.18$ \\
& Diosmetin & $-20.81 \pm 2.96$ \\
& Luteolin & $-20.90 \pm 2.87$ \\
\hline
\end{tabular}

A

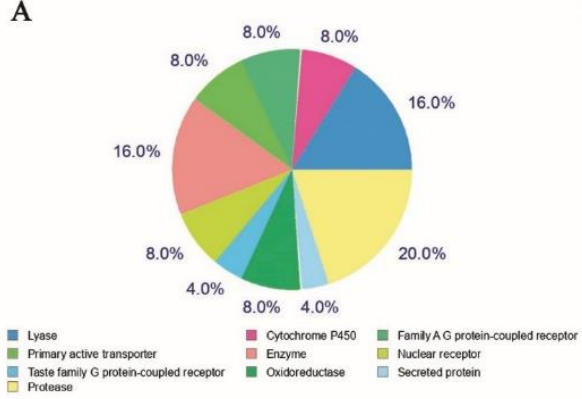

B

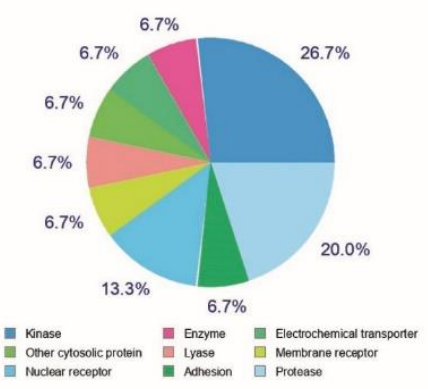

Figure 4. Top-25 of target predicted for top interacted flavonoids (A) Hesperetin, (B) Malvidin. 


\subsection{Molecular dynamic simulation studies}

Molecular dynamics simulation studies were carried out for the top interacting bioactive phytocompounds with target proteins to validate protein-ligand complex, to study protein-ligand complex stability, binding mode prediction and type of interactions with the target protein binding site and top interacting ligands. A frame was captured every $20 \mathrm{~ns}$ during the simulation and saved onto a trajectory. Overall, the simulation exercise produced about 1000 frames.

The parameter root means square deviation (RMSD) provide information about the structural deviation and protein stability. Figure 5 and 6 shows the RMSD of proteins Main protease (Mpro) and Endoribonuclease (NendoU) and selected compounds, and it was observed that the complex was stable for the simulation period. A slight drift was observed in the case of selected compounds in the initial stage of simulation. Still, it was well stable throughout the complete simulation process. No major changes were found in the simulation trajectory as opposed to the protein in the presence of the selected compounds.

To get detail knowledge about the protein-ligand complex, the protein-ligand interactions were also examined during the whole simulation period, and an analysis report was produced for the potential proteinligand interactions (Figure 7 and 8). Some docked compounds demonstrate similar interaction during molecular dynamics simulation, but on the other hand, some compounds show different interaction with protein. Related interactions are observed in most of the situations (Figure 9 and 10).

\section{DISCUSSION}

In silico molecular docking studies can be useful to predict the binding interactions between the phytocompound and the target protein and play a vital role in finding an inhibitor through structure-based drug design. In the current study, we selected SARS-CoV-2 main protease (Mpro) and SARS-CoV-2 endoribonuclease (NendoU) enzymes due to their prominent roles in viral transcription and replication. SARS-CoV-2 main protease (Mpro) plays a vital role in processing and fragmentation of polyproteins into 16 non-structural proteins that forms a replicase-transcriptase complex and perform a variety of enzymatic functions. Non-structural protein 15, an uridylate-specific endoribonuclease (NendoU) is an important enzyme that performs various putative functions in viral replication and sub genomic RNA processing. The selected proteins such as Mpro and NendoU can be considered as highly specific and unique targets for anti$\mathrm{CoV}$ drugs. Molecular docking studies, the molecular interaction on SARS-CoV-2 main protease (Mpro) and SARS-CoV-2 endoribonuclease (NendoU) enzymes indicate their role in the antiviral activity of the phytocompounds.

In this analysis, we rejected those flavonoids that violate Lipinski rule, even though they might have strong molecular interactions with the target protein, were not considered. All the selected flavonoids were

The MolDock scores, ReRank scores and interaction poses of the selected flavonoids were compared with each other against Mpro and NendoU enzymes (Table 4). By analyzing the docking interactions of all selected flavonoids with SARS-CoV-2 main protease, hesperetin bind effectively to the active sites of Mpro such as His41, Asp187, Leu141, Tyr54 and His163 with a MolDock score of $-100.78 \mathrm{kcal} / \mathrm{mol}$, comparable to the known inhibitor N3 (n-[(5-methylisoxazol-3-yl)carbonyl]alanyl-1-valyl-n 1 -((1r,2z)-4-(benzyloxy)-4-oxo-1$\{[(3 r)-2-o x o p y r r o l i d i n-3-y l] m e t h y l\} b u t-2-e n y l)-1-l e u c i n a m i d e)$ as shown in the Table 5, Figure 2. Hesperetin, a naturally occurring flavanone-glycoside (3',5,7-Trihydroxy-4'-methoxyflavanone) usually found in lemons, oranges and citrus honey [23] with a wide range of pharmacological effects including antioxidant, antiinflammatory [24], anti-diabetic [25], anti-allergic, antibacterial and anti-microbial [26]. Hesperetin has been reported to inhibit proteolytic cleavage activity of 3C-like protease of SARS-coronavirus in a dose dependent manner in cell free and cell-based assays.

Malvidin bind effectively at the active sites of NendoU such as Pro344, His235, Lys345 and Lys290 with docked to the SARS-CoV-2 main protease (Mpro) (PDB ID: 6LU7) and endoribonuclease (NendoU) (PDB ID: 6W01) and were compared with the hydrophobic interactions of each other. All the docking procedures were carried out using the grid-based MolDock score (GRID) function with a resolution of $0.30 \mathrm{~A}^{\circ}$.a MolDock score of $-86.51 \mathrm{kcal} / \mathrm{mol}$, comparable with each other due to non-availability of validated inhibitors for SARS-CoV2 [Table 6, Figure 3]. Malvidin, an O-methylated anthocyanidin present in grapes and berries with diverse therapeutic effects including antioxidant, anti-inflammatory [27], antidiabetic [28], neuroprotective [29], antimicrobial [30] and antiviral activities [31]. A comprehensive literature review, docking studies, target and antiviral prediction analysis resulted in considering hesperetin and malvidin inhibitory activities as a potential drugs target against SARS-CoV-2. These small biomolecules predicted substantial pharmacokinetic parameters such as good intestinal absorption, optimum distribution (high protein binding) and does not inhibit p-glycoprotein. The toxicological predictions revelaed that the top interacting ligands exhibits mutagenicity (Ames test), non-carcinogenic in mouse and carcinogenic in rats. 

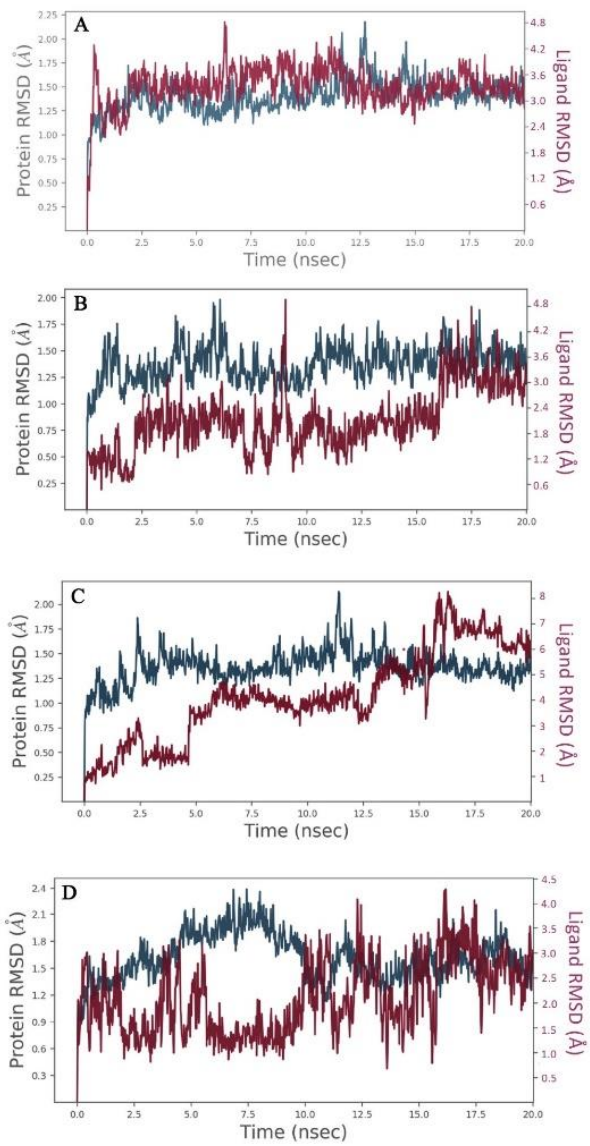

C $\alpha$ Lig fit Prot

Figure 5. Root Mean Square Deviation of the protein-ligand complex of PDB-6LU7 with the top interacting phytocompounds (A) N3 (Co-crystalized ligand), (B) Hesperetin, (C) Peonidin, (D) Quercetin.
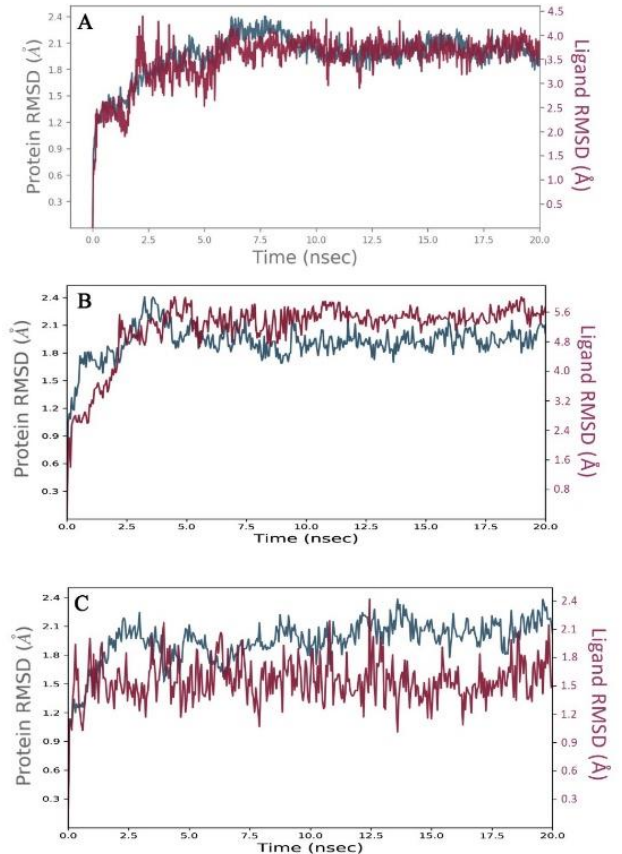

C $\alpha$ Lig fit Prot

Figure 6. Root Mean Square Deviation of the protein-ligand complex of PDB-6W01 with the top interacting phytocompounds (A) Malvidin (B) Silymarin (C) Peonidin. 

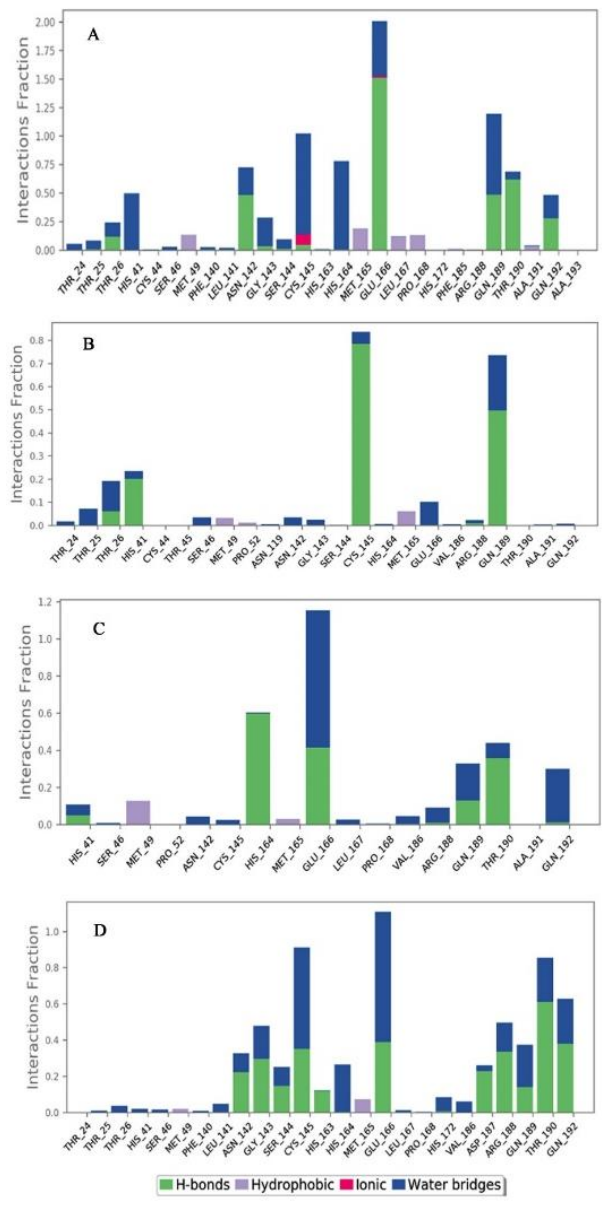

Figure 7. Plot (stacked bar charts) of PDB-6LU7 interactions with the top interacting phytocompounds supervised throughout the simulation (A) N3 (Co-crystalized ligand), (B) Hesperetin, (C) Peonidin, (D) Quercetin.
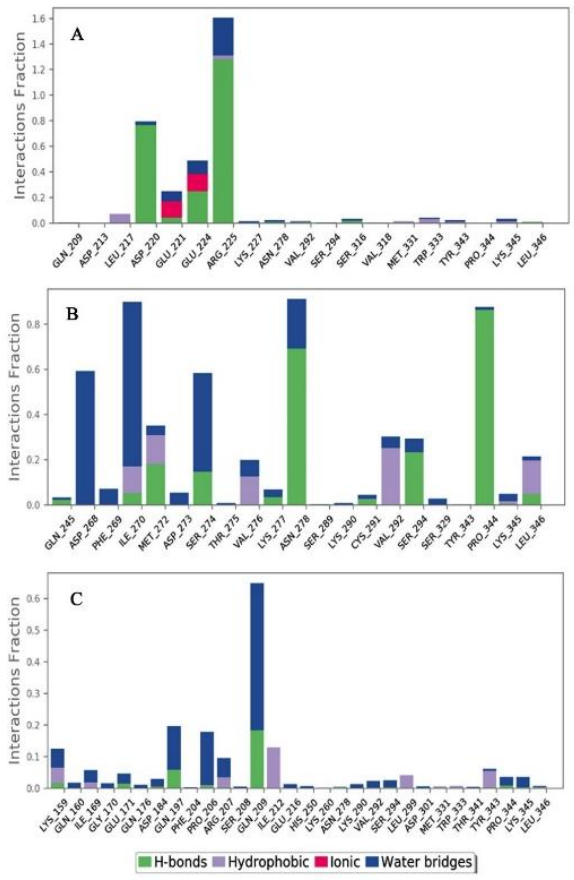

Figure 8. Plot (stacked bar charts) of PDB-6W01 interactions with the top interacting phytocompounds supervised throughout the simulation (A) Malvidin, (B) Silymarin, (C) Peonidin. 

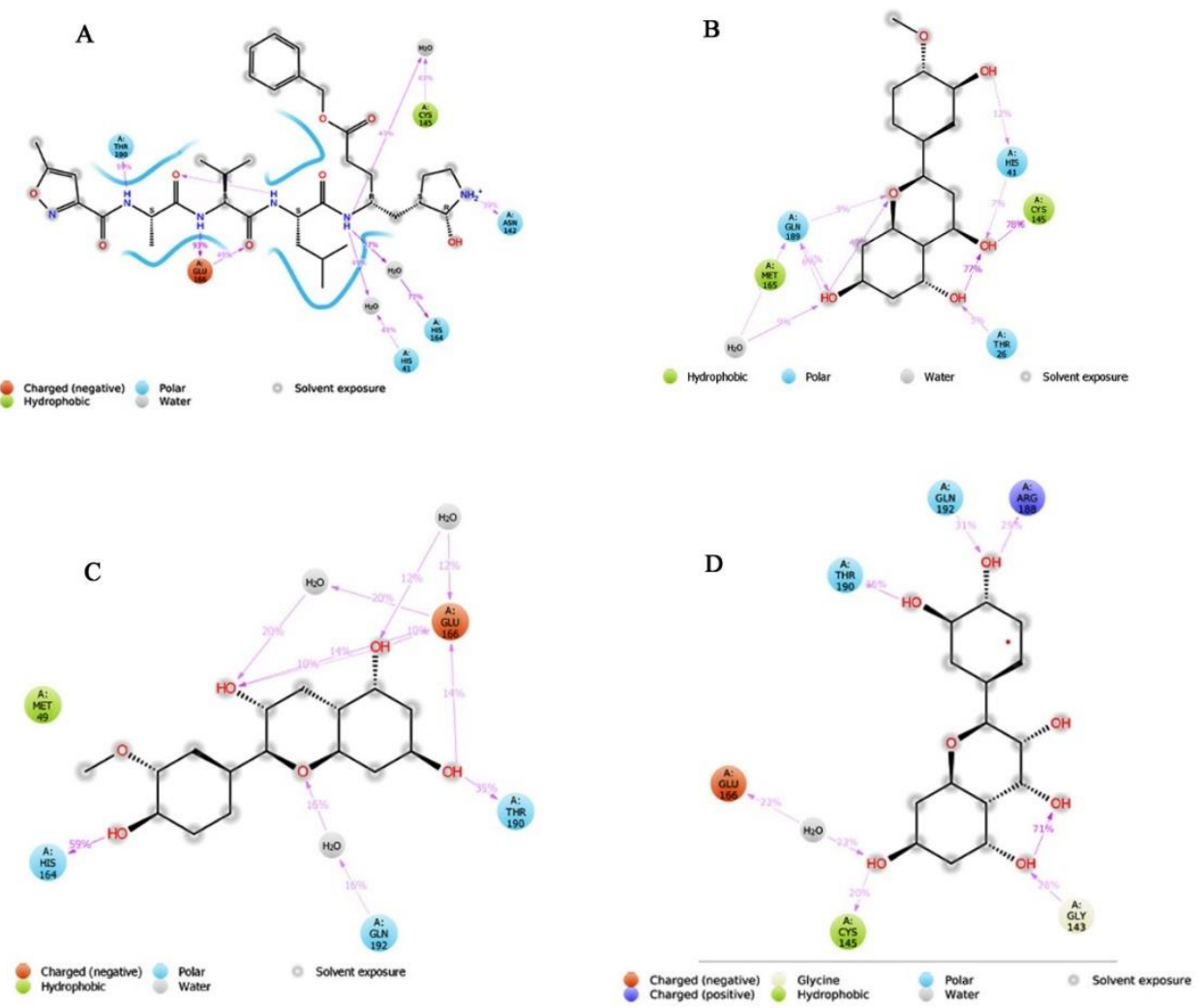

Figure 9. Detailed ligand atomic interactions (2D) with the protein residues of PDB-6LU7 (A) N3 (Cocrystalized ligand), (B) Hesperetin, (C) Peonidin, (D) Quercetin.

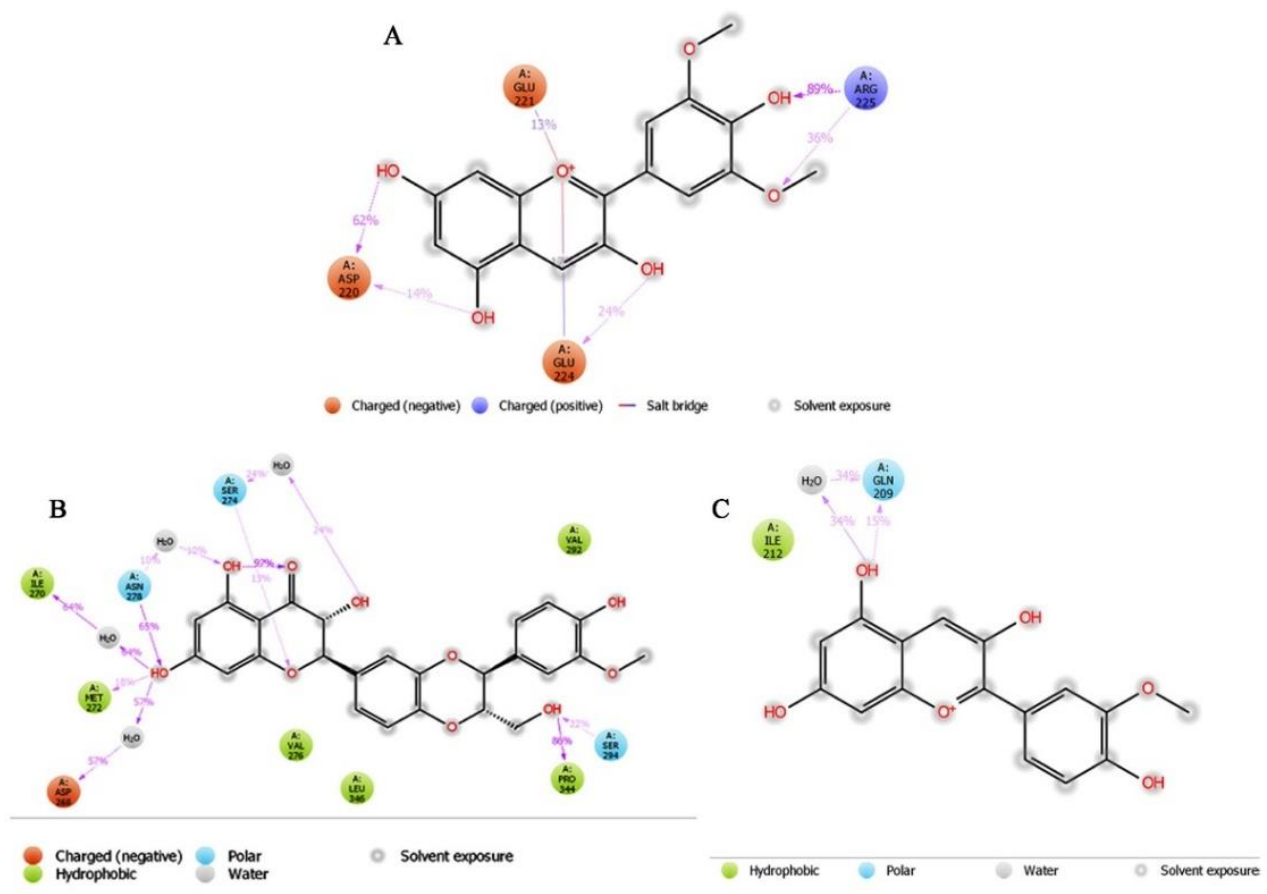

Figure 10. Detailed ligand atomic interactions (2D) with the protein residues of PDB-6W01 (A) Malvidin, (B) Silymarin, (C) Peonidin. 
The assessments revealed that certain flavonoids have docked effectively to SARS-CoV-2 main protease (Mpro) and SARS-CoV-2 endoribonuclease (NendoU) enzyme and showed bioflavonoids to be excellent docking phytocompounds to SARS-CoV-2 protein targets. MM-GBSA binding free energy studies revealed that all the top interacting flavonoids exhibited stability with $\Delta \mathrm{G}$ binding energy $>-20 \mathrm{Kcal} / \mathrm{mol}$. By molecular dynamics simulation study, it was clear that the protein-ligand complex is stable, and it demonstrates good binding interactions of ligands with various amino acids in the target proteins. The binding between hesperetin and protein (PDB-6LU7) revealed substantial hydrogen bond interaction with the amino acid residue Cys145, with 78\% interacted throughout the simulation trajectory. Amino acid residues such as His41, Gln189, Thr26 and Met165 also involved significantly in the bond formation with hesperetin in the active site of 6LU7 [Figure 9A]. Molecular dynamic simulation exhibited similar interaction (Cys145) as that of docking studies indicated that the complex was stable along the trajectory. The malvidin interaction with the protein (PDB-6LU7) revealed significant hydrogen bond interactions with the amino acid residues of Arg225 and Asp220, with $89 \%$ and $62 \%$ interaction in the specified time (Figure 10A). Specific timeline contacts made by the proteins with the interacted ligands throughout the simulation trajectory was presented in Figure 11 and 12. The darker the color indicates more specific contacts between the ligand and amino acids in the protein. The current research created a new perspective in understanding hesperetin and malvidin as potent inhibitors of Mpro and NendoU enzymes respectively, further comparison with validated inhibitors and research in vitro and in vivo may confirm its therapeutic potential in COVID-19. The target and antiviral predications of hesperetin and malvidin also validated the ethnopharmacological knowledge on their antiviral activity.

\section{CONCLUSION}

Currently there is no specific treatment for COVID-19 disease, research is underway to identify lead molecules that could be used as possible anti-viral agents. The aim of this research was to find bioactive flavonoids that could inhibit the SARS-CoV-2 main protease (Mpro) (PDB ID: 6LU7) and endoribonuclease (NendoU) (PDB ID: 6W01). Out of all selected bioflavonoids, hesperetin (-100.78 kcal.mol) and malvidin ($86.51 \mathrm{kcla} / \mathrm{mol}$ ) have shown significant inhibitory activity against main protease and endoribonuclease respectively. These ligands utilize the lowest energy to interact with the target receptors, forming hydrogen bonds with the amino acids in the active site. In conclusion, the current study revealed the importance of bioactive phytocompounds of natural origin in drug discovery and development and can provide opportunities for the development of antiviral agents against COVID-19.

\section{MATERIALS AND METHODS}

\subsection{Drug-like properties}

Drug-likeness is a qualitative, intrinsic and distinctive property of chemical substances that influences the behavior of molecule in the living system and plays an important role in determining their therapeutic efficacy [32]. Drug-like properties such as molecular weight of the compound (MW), Consensus octanol-water partition coefficient $\left(\mathrm{C} \log P_{\mathrm{o}} \mathrm{w}\right)$, number of hydrogen bond donors $(\mathrm{nON})$ and number of hydrogen bond acceptors (nOHNH) were calculated by using SwissADME tool, Swiss Institute of Bioinformatics (https://swissadme.ch) and analyzed for the violations of Lipinski's rule of five [33].

\subsection{ADMET properties}

Pharmacokinetic and toxicological parameters such as absorption, distribution, metabolism, excretion and toxicity of the top interacted ligands were predicted by using online server, PreADMET (https://preadmet.bmdrc.kr) and analyzed based on the properties like BBB penetration $\left(\mathrm{C}_{\text {brain }} / \mathrm{C}_{\text {blood }}\right)$, human intestinal absorption (\%), skin permeability (logKp, cm/hour), water solubility $(\mathrm{mg} / \mathrm{L})$, plasma protein binding (\%), mutagenicity and carcinogenicity effects [34].

\subsection{Retrieval and preparation of ligands}

The 3D structures of the 38 selected flavonoids were retrieved from PubChem online database of National Center for Biotechnology Information (NCBI), U.S. National Library of Medicine, USA. Using ChemBioOffice Ultra 14.0 suite, ligands were preprocessed by adding explicit hydrogens, neutralizing charged groups and minimizing the energy by using the MM2 force field. The processed ligands were optimized and converted into mol file. 


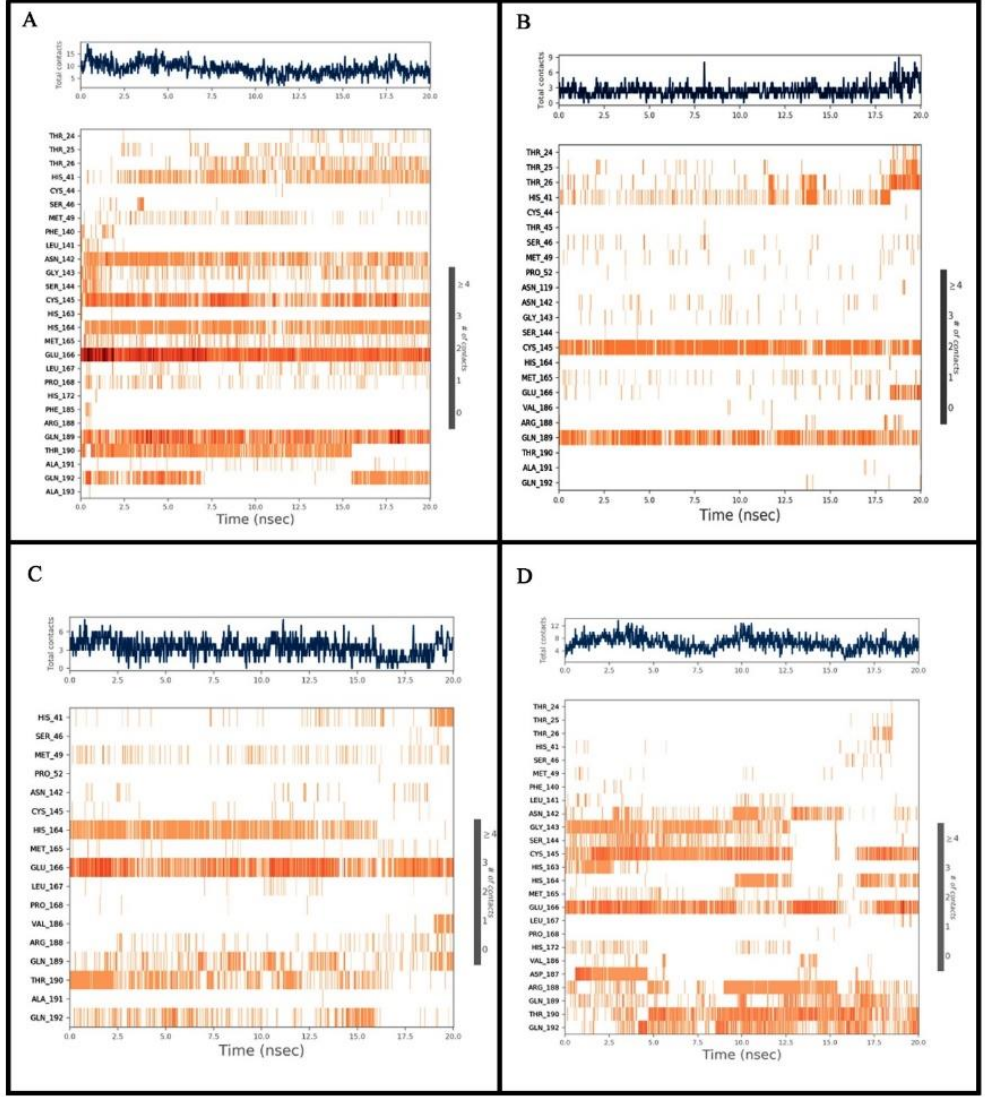

Figure 11. Specific contacts made by the protein (PDB-6LU7) with the ligand throughout the trajectory (A) N3 (Co-crystalized ligand), (B) Hesperetin, (C) Peonidin, (D) Quercetin.

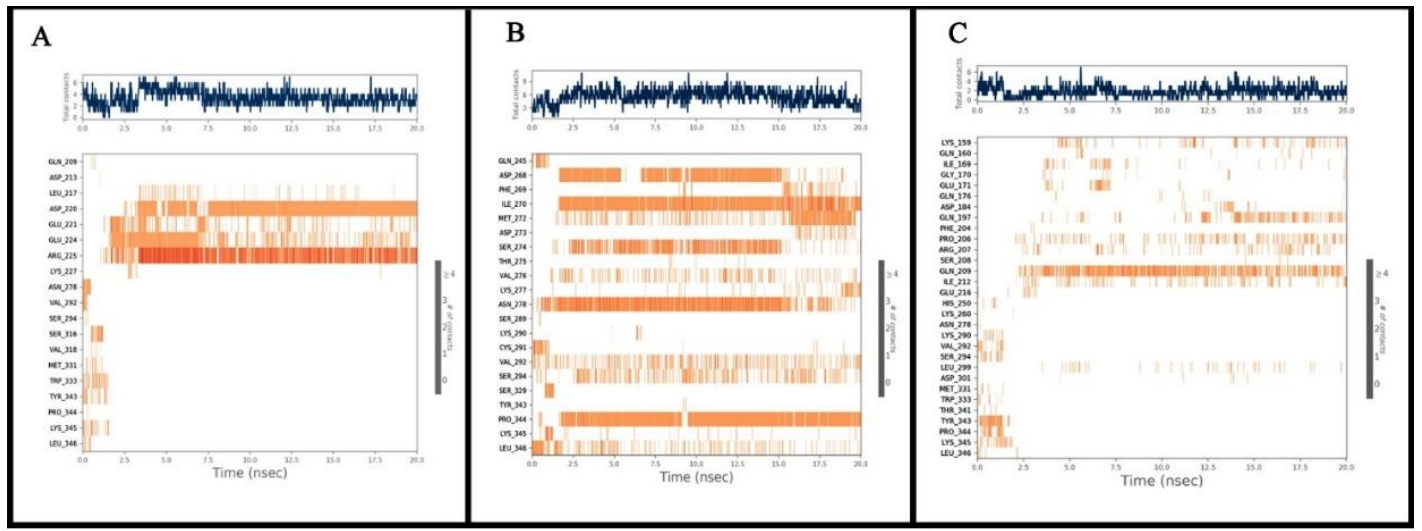

Figure 12. Specific contacts made by the protein (PDB-6W01) with the ligand throughout the trajectory (A) Malvidin, (B) Silymarin, (C) Peonidin.

\subsection{Retrieval and preparation of target proteins}

The 3D X-Ray crystal structures of SARS-CoV-2 main protease (Mpro) complexed with an inhibitor N3 (n-[(5-methylisoxazol-3-yl)carbonyl]alanyl-1-valyl-n 1 -((1r,2z)-4-(benzyloxy)-4-oxo-1-\{[(3r)-2-

oxopyrrolidin-3-yl]methyl\}but-2-enyl)-l-leucinamide) (PDB ID: 6LU7 with resolution of 2.16 $\mathrm{A}^{\circ}$ ) [35] and SARS-CoV-2 endoribonuclease (NendoU) complexed with citrate (PDB ID: 6W01 with resolution of $1.9 \mathrm{~A}^{\circ}$ ) [8] were retrieved from Research Collaboratory for Structural Bioinformatics Protein Data Bank (RCSB PDB) (https://rcsb.org/search) (Figure 1). The raw proteins were pre-processed and prepared by removing ligands and water molecules, valency correction by adding implicit hydrogen atoms and fixing crystallographic disorders by assigning bond angles, bond orders and topology. Then the proteins were subject to refinement and energy minimization before performing docking studies. 
(A)

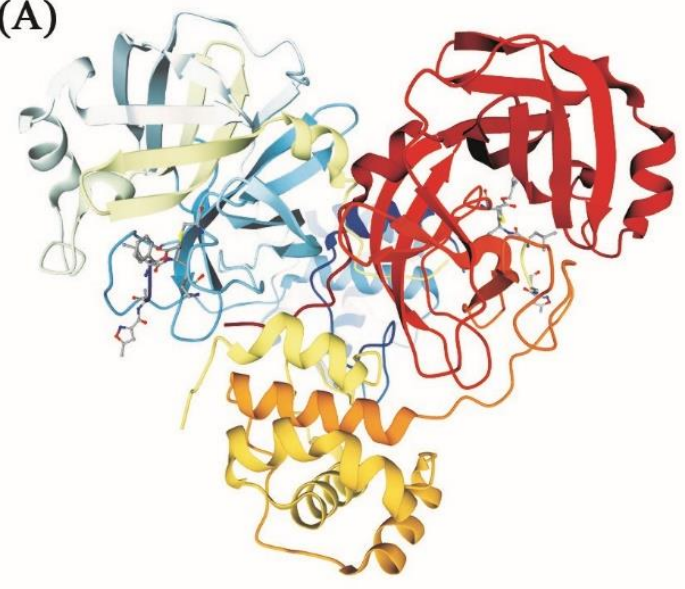

(B)

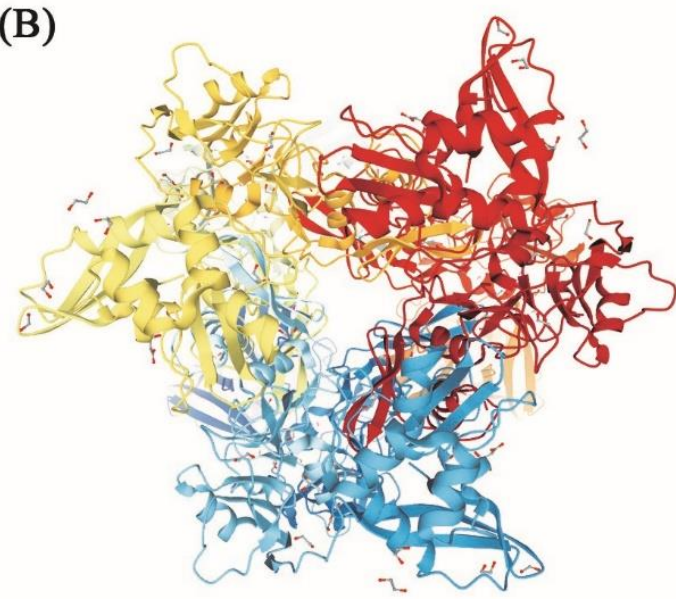

Figure 1. Crystal structures of SARS-CoV-2 target proteins (A) Main protease (Mpro) complexed with an inhibitor N3, (B) Endoribonuclease (NendoU) complexed with citrate.

\subsection{Validation of target protein-ligand complex structures}

The Molegro Virtual Docker v6.0 algorithm was to be validated first for the crystal structures of the target proteins to ensure that ligands docked using the Molegro Virtual Docker (MVD) represent valid MolDock score and accurate binding with target receptor. In this context, Mpro (PDB ID: 6LU7) was tested with its co-crystalized inhibitor N3 (n-[(5-methylisoxazol-3-yl)carbonyl]alanyl-1-valyl-n 1 - ((1r,2z)-4-(benzyloxy)4-oxo-1-\{[(3r)-2-oxopyrrolidin-3-yl]methyl\}but-2-enyl)-1-leucinamide) and NendoU (PDB ID: 6W01) was tested with its co-crystalized citrate.

\subsection{Molecular docking studies}

Molecular docking studies were performed to understand the ligand-receptor interaction and affinity of selected phytocompounds against Mpro and NendoU enzymes using Molegro Virtual Docker v6.0 in PC with 8GB RAM and an Intel Core i5-8250U CPU @1.60GHz processor running Windows 10. All phytocompounds were docked at the selected active site in the target protein with default input parameters such as molecular surface (expanded van der Waals), maximum number of cavities $(n=5)$, probe size (1.20), maximum number of steps per residue $(n=10,000)$, maximum number of global steps $(n=10,000)$, minimum cavity volume (10) and grid resolution (0.80) were used to detect better potential binding sites in the protein. In the recent studies, many antiviral drugs with known efficacy were used in validation studies to identify a potential inhibitor from the natural source. Lopinavir, a protease inhibitor in supressing the shedding of SARSCoV-2 were used in validation studies for main protease (Mpro) (PDB ID: 6LU7) [36] and endoribonuclease (NendoU) (PDB ID: 6W01) [37]. FDA approved antiviral drugs such as Ribavirin (HCV polymerase inhibitor) and Remdesivir (RNA polymerase inhibitor) were used as reference compounds against main protease in finding a potent inhibitor from the phytocompounds of Momordica charantia and Azadirachta indica [38]. Stuides revealed that Darunavir (antiretroviral) exhibits highest docking scores against Mpro and NendoU when compared with Remdesivir, Favipiravir, Umiferovir, Lopinavir, Galidesivir, Velapatasvir and Danoprevir and were used as reference drugs in repurposing of the herbal formulations [38]. However, the MolDock scores (GRID), ReRank scores and HBond of the natural phytocompounds docked into the target proteins were calculated, best interaction poses were analyzed and compared against Mpro and NendoU enzymes to find the best hit of all the phytocompounds.

\subsection{Target and antiviral prediction}

The antiviral properties of the phytocompounds were predicted based on structural characteristics by comparing with the database containing 2,50,000 biological active substances using prediction of activity spectra for substances (PASS) online prediction tool and can be used effectively to identify new ligand targets and, contrarywise, to reveal new ligands for certain biological targets [39]. 


\subsection{Binding free energy (MM-GBSA) studies}

For free binding energy calculation, Prime MM/GBSA (Molecular Mechanics Energies Generalized Born and Surface Area Continuum Solvation) module was used [40]. The prime MM / GBSA system relies on the VSGB solvation process, which uses a generalized variable-dielectric Born model and water as a solvent in the OPLS3e force field to measure binding energy. The receptor's flexibility in grid-based docking systems like XP is limited.

\subsection{Molecular dynamics simulation studies}

Molecular dynamics simulation was widely used to understand the functionality and dynamics of protein and protein-ligand systems. Molecular docking does not represent the real biological processes, in which the protein and ligand are solvated in water. Therefore, molecular dynamics simulation was performed to tackle this problem. The docked protein-ligand complex was further used for the molecular dynamic's simulation studies. For a better understanding of the protein's dynamic behaviour in the presence of ligand, molecular dynamics simulation was performed using Desmond integrated with Maestro. In the current research, Schrodinger, LLC's Maestro Molecular Platform (version 11.8) was used to conduct molecular dynamics simulation experiments with Linux Ubuntu 18.04.1 LTS platform, NVidia graphics card, 8 GB Ram, and Intel Core i3-4160 processor on an HP desktop system.

Molecular dynamics simulation is a three-step process in which the first step is system builder, second minimization and finally the dynamics. For the simulation, the OPLS3e force field was used. In the system builder, the solvent model was selected as SPC (simple point charge) model, which was put in an orthorhombic box, and the method of measurement of box size was Buffer. Sodium and chloride ions were used to neutralize the charges. Then the energy minimization and equilibration of the prepared system was done. Temperature and pressure were set, respectively at $300 \mathrm{~K}$ and 1.01325 bar via NPT ensemble. The recording interval of trajectory is $20 \mathrm{~ns}$. The simulation study was analyzed using Simulation Interaction Diagram of Desmond. Molecular dynamics simulation study for $20 \mathrm{~ns}$ was carried out for the best docking score showing compounds.

Acknowledgements: The authors are grateful to the management College of Pharmacy, Koneru Lakshmaiah Education Foundation, Vaddeswaram, A.P and Manipal-Schrödinger Centre for Molecular Simulations, for providing required research facilities to carry out the research work.

Author contributions: Concept - U.S.G, K.R.G.S.N.K.; Design - U.S.G, K.R.G.S.N.K., A.J.; Supervision - U.K., R.R.A.; Resources - U.S.G., U.K., S.D.; Materials - U.S.G.; Data Collection and/or Processing - U.S.G., K.R.G.S.N.K.; Analysis and/or Interpretation - U.S.G, K.R.G.S.N.K., U.K., R.R.A., A.J.; Literature Search - U.S.G, K.R.G.S.N.K., A.J.; Writing U.S.G.; Critical Reviews - U.S.G, K.R.G.S.N.K., U.K., A.J.

Conflict of interest statement: We wish to confirm that there are no known conflicts of interest associated with this publication and there has been no significant financial support for this work that could have influenced its outcome.

\section{REFERENCES}

[1] Dhama K, Sharun K, Tiwari R, Dadar M, Malik YS, Singh KP, Chaicumpa W. COVID-19, an emerging coronavirus infection: advances and prospects in designing and developing vaccines, immunotherapeutics, and therapeutics. Hum Vaccin Immunother. 2020; 16(6): 1-7. [CrossRef]

[2] Baldwin R, di Mauro BW, Economics in the Time of COVID-19, a VoxEU.org eBook, CEPR Press 2020.

[3] Li LQ, Huang T, Wang YQ, Wang ZP, Liang Y, Huang TB, Zhang HY, Sun W, Wang, Y. 2019 novel coronavirus patients' clinical characteristics, discharge rate and fatality rate of meta-analysis. J Med Virol. 2020; 92: 577-583. [CrossRef]

[4] Zhang H, Penninger JM, Li Y, Zhong N, Slutsky AS. Angiotensin-converting enzyme 2 ACE2 as a SARS-CoV-2 receptor: molecular mechanisms and potential therapeutic target. Intensive Care Med. 2020; 46(4): 586-590. [CrossRef]

[5] Uma SG, Rao GSNK. SARS-CoV-2: The prominent role of non-structural proteins Nsps in COVID-19. Indian J Pharm Edu Res. 2020; 54: s381-s389. [CrossRef]

[6] Hoffmann M, Kleine-Weber H, Schroeder S, Kruger N, Herrler T, Erichsen S, Schiergens TS, Herrler G, Wu NH, Nitsche A, Muller MA, Drosten C, Pohlmann S. SARS-CoV-2 cell entry depends on ACE2 and TMPRSS2 and is blocked by a clinically proven protease inhibitor. Cell. 2020; 181: 271-280. [CrossRef] 
[7] Khan RJ, Jha RK, Amera GM, Jain M, Singh E, Pathak A, Singh RP, Muthukumaran J, Singh AK. Targeting SARSCoV-2: a systematic drug repurposing approach to identify promising inhibitors against 3c-like proteinase and 2'-Oribose methyltransferase. J Biomol Struct Dyn. 2020; 1-14. [CrossRef]

[8] Kim Y, Jedrzejczak R, Maltseva NI, Wilamowski M, Endres M, Godzik A, Michalska K, Joachimiak A. Crystal structure of Nsp15 endoribonuclease NendoU from SARS-CoV-2. Protein Sci. 2020; 29(7): 1596-1605. [CrossRef]

[9] Lu H. Drug treatment options for the 2019-new coronavirus 2019-nCoV. Biosci Trends. 2020; 14(1): 69-71. [CrossRef]

[10] Prajapat M, Sarma P, Shekhar N, Avti P, Sinha S, Kaur H, Kumar S, Bhattacharyya A, Kumar H, Bansal S, Medhi B. Drug targets for corona virus: A systematic review. Indian J Pharmacol. 2020; 52(1): 56-65. [CrossRef]

[11] Gautret P, Lagier JC, Parola P, Hoang VT, Meddeb L, Mailhe M, Doudier B, Courjon J, Giordanengo V, Vieira VE, Dupont HT, Honore S, Colson P, Chabriere E, Scola BL, Rolain JM, Brouqui P, Raoult D. Hydroxychloroquine and azithromycin as a treatment of COVID-19: results of an open-label non-randomized clinical trial. Int J Antimicrob. 2020; 56(1): 105949. [CrossRef]

[12] Aanouz I, Belhassan A, El-Khatabi K, Lakhlifi T, El-Idrisi M, Bouachrine M. Moroccan medicinal plants as inhibitors against SARS-CoV-2 main protease: Computational investigations. J Biomol Struct Dyn. 2020; 1-9. [CrossRef]

[13] Pietta PG. Flavonoids as antioxidants. J Nat Prod. 2000; 63(7): 1035-1042. [CrossRef]

[14] Maleki S, Crespo JF, Cabanillas B. Anti-inflammatory effects of flavonoids. Food Chem. 2019; 299: 125124. [CrossRef]

[15] Xie Y, Yang W, Tang F, Chen X, Ren L. Antibacterial activities of flavonoids: structure-activity relationship and mechanism. Curr Med Chem. 2015; 22(1): 132-149. [CrossRef]

[16] Stapel J, Oppermann C, Richter DU, Ruth W, Briese V. Polyphenol compounds with anti-carcinogenic qualities: effects of quercetin flavonol, chrysin flavon, kaempferol flavanol, naringenin flavanon and hesperidin flavanoid on in vitro breast cancer. J Med Plant Res. 2013; 7(29): 2187-2196. [CrossRef]

[17] Kawaii S, Tomono Y, Katase E, Ogawa K, Yano M. Antiproliferative activity of flavonoids on several cancer cell lines. Biosci Biotechnol Biochem. 1999; 63(5): 896-899. [CrossRef]

[18] Gorla US, Rao GSNK, Kulandaivelu US, Alavala RR, Panda SP. Lead finding from selected flavonoids with antiviral SARS-CoV-2 potentials against COVID-19: An in-silico evaluation. Comb Chem High Throughput Screen. 2020; 24(6): 879-890. [CrossRef]

[19] Galluzzo P, Marino M. Nutritional flavonoids impact on nuclear and extranuclear estrogen receptor activities. Genes Nutr. 2006; 1(3-4): 161-176. [CrossRef]

[20] Dai W, Bi J, Li F, Wang S, Huang X, Meng X, Sun B, Wang D, Kong W, Jiang C, Su W. Antiviral Efficacy of Flavonoids against Enterovirus 71 Infection in vitro and in Newborn Mice. Viruses. 2019; 11(7): 625. [CrossRef]

[21] Gombar VK, Silver IS, Zhao Z. Role of ADME characteristics in drug discovery and their in-silico evaluation: in silico screening of chemicals for their metabolic stability. Curr Top Med Chem. 2003; 3(11): 1205-1225. [CrossRef]

[22] Aliper A, Plis S, Artemov A, Ulloa A, Mamoshina P, Zhavoronkov A. Deep learning applications for predicting pharmacological properties of drugs and drug repurposing using transcriptomic data. Mol Pharm. 2016; 13(7): 25242530. [CrossRef]

[23] Ferreres F, García-Viguera C, Tomás-Lorente F, Tomas-Barberan FA. Hesperetin: A marker of the floral origin of citrus honey. J Sci Food Agric. 1993; 61(1): 121-123. [CrossRef]

[24] Yang HL, Chen SC, Senthil Kumar KJ, Yu KN, Lee Chao PD, Tsai SY, Hou YC, Hseu YC. Antioxidant and antiinflammatory potential of hesperetin metabolites obtained from hesperetin-administered rat serum: an ex vivo approach. J Agric Food Chem. 2012; 60(1): 522-532. [CrossRef]

[25] Jayaraman R, Subramani S, Abdullah SHS, Udaiyar M. Antihyperglycemic effect of hesperetin, a citrus flavonoid, extenuates hyperglycemia and exploring the potential role in antioxidant and antihyperlipidemic in streptozotocininduced diabetic rats. Biomed Pharmacother. 2018; 97: 98-106. [CrossRef]

[26] Iranshahi M, Rezaee R, Parhiz H, Roohbakhsh A, Soltani F. Protective effects of flavonoids against microbes and toxins: The cases of hesperidin and hesperetin. Life Sci. 2015; 137: 125-132. [CrossRef]

[27] Wang H, Nair MG, Strasburg GM, Chang YC, Booren AM, Gray JI, DeWitt DL. Antioxidant and antiinflammatory activities of anthocyanins and their aglycon, cyanidin, from tart cherries. J Nat Prod. 1999; 62(2): 294-296. [CrossRef]

[28] Grace MH, Ribnicky DM, Kuhn P, Poulev A, Logendra S, Yousef GG, Raskin I, Lila MA. Hypoglycemic activity of a novel anthocyanin-rich formulation from lowbush blueberry, Vaccinium angustifolium Aiton. Phytomedicine. 2009; 16(5): 406-415. [CrossRef] 
[29] Strathearn KE, Yousef GG, Grace MH, Roy SL, Tambe MA, Ferruzzi MG, Wu QL, Simon JE, Lila MA, Rochet JC. Neuroprotective effects of anthocyanin-and proanthocyanidin-rich extracts in cellular models of Parkinson's disease. Brain Res. 2014; 1555: 60-77. [CrossRef]

[30] Cisowska A, Wojnicz D, Hendrich AB. Anthocyanins as antimicrobial agents of natural plant origin. Nat Prod Commun. 2011; 6(1): 149-156. [CrossRef]

[31] Pour PM, Fakhri S, Asgary S, Farzaei MH, Echeverria J. The signalling pathways, and therapeutic targets of antiviral agents: Focusing on the antiviral approaches and clinical perspectives of anthocyanins in the management of viral diseases. Front Pharmacol. 2019; 10: 1207. [CrossRef]

[32] Ursu O, Rayan A, Goldblum A, Oprea TI. Understanding drug-likeness. Wiley Interdiscip Rev Comput Mol Sci. 2011; 1(5): 760-781. [CrossRef]

[33] Lipinski CA. Lead-and drug-like compounds: the rule-of-five revolution. Drug Discov Today Technol. 2004; 1(4): 337-341. [CrossRef]

[34] Daina A, Michielin O, Zoete V. SwissADME: a free web tool to evaluate pharmacokinetics, drug-likeness and medicinal chemistry friendliness of small molecules. Sci Rep. 2017; 7: 42717. [CrossRef]

[35] Jin Z, Du X, Xu Y, Deng Y, Liu M, Zhao Y, Zhang B, Li X, Zhang L, Peng C, Duan Y, Yu J, Wang L, Yang K, Liu F, Jiang R, Yang X, You T, Liu X, Yang X, Bai F, Liu H, Liu X, Guddat LW, Xu W, Xiao G, Qin C, Shi Z, Jiang H, Rao Z, Yang H. Structure of Mpro from SARS-CoV-2 and discovery of its inhibitors. Nature. 2020; 582(7811): $289-293$. [CrossRef]

[36] Gupta S, Singh AK, Kushwaha PP, Prajapati KS, Shuaid M, Senapati S, Kumar S. Identification of potential natural inhibitors of SARS-CoV2 main protease by molecular docking and simulation studies. J Biomol Struct Dyn. 2020; 2020: 1-12. [CrossRef]

[37] Vijayan R, Gourinath S. Structure-based inhibitor screening of natural products against NSP15 of SARS-CoV-2 revealed thymopentin and oleuropein as potent inhibitors. J Proteins Proteom. 2021; 12: 71-80. [CrossRef]

[38] Joshi C, Chaudhari A, Joshi C, Joshi M, Bagatharia S. Repurposing of the herbal formulations: molecular docking and molecular dynamics simulation studies to validate the efficacy of phytocompounds against SARS-CoV-2 proteins. J Biomol Struct Dyn. 2021; 2021: 1-15. [CrossRef]

[39] Lagunin A, Stepanchikova A, Filimonov D, Poroikov V. PASS: prediction of activity spectra for biologically active substances. Bioinformatics. 2000; 16(8): 747-748. [CrossRef]

[40] Rathi E, Kumar A, Kini SG. Molecular dynamics guided insight, binding free energy calculations and pharmacophore-based virtual screening for the identification of potential VEGFR2 inhibitors. J Recept Sig Transd. 2019; 39(5-6): 415-433. [CrossRef]

This is an open access article which is publicly available on our journal's website under Institutional Repository at http://dspace.marmara.edu.tr. 